\title{
On Oxidative Degradation of Parchment and Its Non-destructive Characterisation and Dating
}

\author{
Alenka Možir ${ }^{1}$, Matija Strlič ${ }^{2 *}$, Tanja Trafela ${ }^{1}$, Irena Kralj Cigić ${ }^{1}$, Jana Kolar $^{3}$, Viorica Deselnicu ${ }^{4}$, \\ Gerrit de Bruin ${ }^{5}$
}

1. University of Ljubljana, Faculty of Chemistry and Chemical Technology, Aškerčeva 5, SI-1000 Ljubljana, Slovenia

2. Centre for Sustainable Heritage, The Bartlett School of Graduate Studies, University College of London, Gower Street (Torrington Place site), London WCIE 6BT, United Kingdom

3. Morana RTD d.o.o., Oslica 1b, SI-1295 Ivančna Gorica, Slovenia

4. INCDTP- Branch Leather-Footwear Research Institute, Ion Minulescu 93, 3rd Sector, Bucharest, Romania

5. Nationaal Archief, The Hague, Prins Willem Alexanderhof 20, 2509 LM The Hague, The Netherlands

*corresponding author: m.strlic@ucl.ac.uk

\begin{abstract}
Historic parchment is an extremely complex material, not only due to the various methods of production used and various past environmental histories of objects, but also due to its inhomogeneous structure. Many traditional methods of characterisation are empirical, but useful since they have gained recognition by the end-users. In this paper, we investigated the shrinkage temperature of collagen and the influence of lipids contained in parchment on the measurements. While the content of lipids does not seem to significantly affect shrinkage temperature measurements themselves, it strongly affects the decrease of shrinkage temperature of collagen during degradation, and thus its thermomechanical properties. This confirms the high importance of lipid peroxidation during degradation of parchment.

While shrinkage temperature determination is a micro-destructive method, we also demonstrated that it is possible to determine this property using near infrared (NIR) spectroscopy based on partial least squares calibration. The root-mean square error of validation (RMSEV), obtained on a set of variously delipidised and degraded samples, was $7{ }^{\circ} \mathrm{C}$, so the method could be used for condition assessment or classification of historic objects. Using a set of 185 historic objects dating from 1200-1800, we also developed a method for non-destructive dating of parchment based on NIR spectroscopy using partial least squares calibration (RMSEV $=72$ years), and successfully determined the correct age of a historic charter from the collection of Nationaal Archief, The Netherlands.
\end{abstract}

\section{KEYWORDS}

Near infrared spectroscopy; Chemometrics; Lipid peroxidation; Collagen; Conservation; Cultural heritage

\section{PACS}

82.80.Gk, 81.40.-z; 81.70.Fy; 83.80.Lz 


\section{INTRODUCTION}

Parchment is a complex natural material made from animal skin, which has been used for centuries as a writing support and for bookbinding. It replaced papyrus due to several advantages, such as suitable mechanical properties and the possibility of ink removal and material reuse. Due to the historic value of objects made of parchment, understanding of their degradation and their condition is of high importance to archives, libraries and museums [1-4].

Parchment consists mainly of collagen type I, with some lipids, water and inorganic matter. Collagen has a unique triple helix structure, which is stabilized by hydrogen bonds and van der Waal's interactions between side chains [5]. The helix structure plays an important role in its mechanical properties. Numerous denaturation processes, biological and non-biological, lead to degradation of this ordered structure, converting it into unfolded and disordered gelatine. This leads to fragility and brittleness of parchment objects [6]. In terms of material stability, hydrothermal properties of parchment are of major interest and much research has so far been focused on thermal and structural methods of analysis. However, studies of historic materials are difficult due to unknown storage history, production methods and inhomogeneous composition and structure [7], and techniques from macro to nanoscale may be necessary [8]. Shrinkage temperature has been reported to be a good indicator of hydrothermal stability, and indicative of the level of deterioration of collagen fibres [9, 10]. The higher the shrinkage temperature, the more energy is needed for bonds to break between collagen molecules, thus indicating better condition of the parchment object [9-13]. Other thermal methods to study the condition of parchment have been suggested [6,11-14], one of the most commonly used methods being differential scanning calorimetry (DSC) [9, 15]. However, shrinkage temperature seems to remain the most widely understood by the end-user community [16].

It was recently shown that lipid content in parchment may have an important influence on collagen degradation [4], probably via autoxidation [7]. In the oxidation processes of skin tissue, protein, carbohydrates and lipids are all targets for reactive oxygen species (ROS) [17, 18]. During the process of reaction of proteins with reactive oxygen species, an increase of carbonyl groups in the protein macromolecule was detected, indicating degradation of the peptide chain [7]. On the other hand, changes in the structure of collagen may be indirectly caused by autoxidation of carbohydrates and lipids $[7,17,18]$. The lipid fraction, undergoing autoxidation in the presence of atmospheric oxygen, was observed to lead to damage observed on proteins $[4,7,17,18]$. For parchment, a direct link between lipid content and collagen degradation has, however, still not been demonstrated.

Recently, a comprehensive review of parchment degradation and methods of characterisation has been published [19]. Many analytical methods of identification and characterisation of historic materials are often time-consuming and destructive or micro destructive [1-4]. Outside the laboratory, analytical methods that do not involve sample preparation and have rapid and easy access to data are often preferred. Near-infrared (NIR) spectroscopy in conjunction with multivariate analysis could represent an attractive option, however, it has not been used for parchment characterization yet [20-22].

However, it has recently been shown to be appropriate for qualitative and quantitative characterisation of historic paper [21].

Spectra in the NIR region are composed of overtones and combination vibrations, especially of $\mathrm{NH}$, $\mathrm{CH}$, and $\mathrm{OH}$ functionalities [22]. Because of the overlaps and since various functionalities exhibit 
absorptions multiple times across the NIR spectrum, it is necessary to extract the useful information using multivariate chemometric data analysis, such as principal component analysis (PCA) [22-25] or partial least square calibration (PLS) [21, 24, 25]. The objective of PCA is to reduce the dimensionality (number of variables) of the dataset, but retain most of the original variability in the data. PCA analysis is used for visualisation of complex data sets according to their similarities and differences [23-25]. On the other hand, PLS enables spectral and measured/observed information to be correlated. The quality of results in both cases depends on a number of factors, among which the quality of NIR spectra, and the quality of the reference method and the associated chemical analytical data are the most important $[23,24]$.

The goal of the research presented here was to introduce NIR spectroscopy as a non-destructive spectroscopic method of analysis and characterization of proteinaceous historic materials. We investigated 185 historic parchments of different environmental histories, age and condition, and a dating method is proposed based on NIR spectroscopy and multivariate data analysis. Shrinkage temperature of 90 parchment samples was determined to examine the relations between lipid content and degradation of parchment. With a set of differently de-lipidised and degraded parchment samples, we provide a positive proof of the effect of lipid content on parchment degradation.

\section{MATERIALS AND METHODS}

Samples. 209 parchment documents and samples of parchment were used. The samples were analysed in two separate sets as described below.

Set I. Samples from this set were used in the shrinkage temperature study and were comprised of 24 historic samples of parchment of various origins, purchased in antique shops or obtained through donations, and produced between 1480 and 1900, including a new goat parchment sample from 2005 (goat parchment, Talas, New York). These samples were both documents and bookbinding parchments.

Lipids were extracted from the parchment samples with hexane (HPLC grade, J.T.Baker, USA) using Soxhlet extraction, the duration was $0 \mathrm{~h}$ (immersion only), $1 \mathrm{~h}$ and $4 \mathrm{~h}$. After extraction, the samples were dried in vacuum and equilibrated at room temperature.

Half of all samples (extracted and non-extracted) were then subjected to accelerated degradation in a climatic chamber (Vötsch Climatic chamber, Type VC 0020) at $80{ }^{\circ} \mathrm{C}$ and $65 \% \mathrm{RH}$ for 18 days. The other half was not subjected to degradation.

Set II. 185 historic objects from this set were analysed non-destructively using NIR spectroscopy, on the premises of Nationaal Archief (The Hague, The Netherlands). The parchment documents originated between 1179 and 1793 .

Shrinkage temperature. The shrinkage temperature of parchment samples from Set I was determined using a micro hot table (Caloris, Bucharest) connected with a stereo microscope Leica S4E (20-160x). The temperature was programmed using FLTK 1.1.9. software (GNU Lesser General Public License). A high resolution Leica EC3 camera was used for visual determination of shrinkage temperature. 
A few collagen fibres were sampled with a scalpel and placed in distilled water on a microscope slide with a central concavity. After separation of the fibres, the samples were covered with a slide and placed on the micro hot table. The temperature programme was started at room temperature and increased at $2{ }^{\circ} \mathrm{C} \mathrm{min}^{-1}$ until the temperature at which shrinking was just observed (this temperature was noted), and then continued until the process completed.

The average standard deviation of shrinkage temperature measurement was $0.6-0.8{ }^{\circ} \mathrm{C}$, and the RSD 1$1.5 \%$. The average standard deviation and RSD were determined from five independent measurements of sample $(\mathrm{N}=5)$.

Spectroscopic Analysis. A portable LabSpec 5000 ASD NIR spectrometer (Boulder, CO) with two separate attachments was used: ASD Chem Probe with a purpose-made accessory and ASD MuGLight.

The ASD Chem Probe is a small-diameter fibre optics probe for contact reflectance measurements. The diameter of the fibre is $2 \mathrm{~mm}$. The purpose-made accessory enables the light to impact on the object at a $45^{\circ}$ angle and the reflected light is collected at the same angle. This allows for collection of diffusely reflected spectra on an area of $2 \times 3 \mathrm{~mm}$. The ASD MuG-Light has an independent halogen light source installed and thus allows for higher intensity illumination and therefore better quality spectra. The measurement area is $12 \mathrm{~mm}$ in diameter.

The reflectance spectra were collected in the interval of 350-2500 nm, 100 scans per spectrum. Five measurements were taken on five different positions of the same sample, with a set of positions on the recto and another set on the verso side. As a background, a stack of pure cellulose filter paper sheets was used (Whatman No. 1, Maidstone).

Chemometric Data Analysis. Principal component analysis (PCA) and partial least square analysis (PLS) were performed using Unscrambler v.9.7 (CAMO, Trondheim).

PLS analysis was used to build the models for determination of shrinkage temperature and year of production of parchment. Independent sample sets were used for calibration and validation. Optimal correlations were sought by using different spectral pre-treatments (Standard normal variate - SNV, derivatives). Martens' uncertainty test was used to determine the significant wavelengths. To evaluate the quality of calibration the root mean square error of calibration (RMSEC) and cross validation (RMSECV) were calculated. To evaluate the quality of estimation the root mean square error of validation (RMSEV) was calculated [21].

\section{RESULTS AND DISCUSION}

\section{The influence of lipids on parchment degradation}

Collagen molecule has the structure of a triple helix [5] and during ageing, its helical structure transforms into a random gelatinous structure, which is accompanied by decreased shrinkage temperature of the material $[6,9]$. Shrinkage temperature can easily be measured using thermal microscopy, using only a small amount of a sample [10]. The higher the shrinkage temperature, the better is the condition of the parchment object [9-13]. 
Due to the limited availability of historic parchment samples, and in order to examine the effect of lipids on parchment degradation, we first expanded Set I consisting of 12 historic samples by differentially de-lipidising them. This was done by Soxhlet extraction with hexane for 1 and $4 \mathrm{~h}$, and the amount of extracted material was determined gravimetrically. However, only 8 samples were available in a quantity large enough to perform this experiment.

The new goat parchment was sampled on the back, the front and the leg, and the three sets were considered as separate samples due to the different skin structure and tension applied during parchment preparation. The shrinkage temperature of the three parts was: front: $71.2{ }^{\circ} \mathrm{C}$, back: $69.1{ }^{\circ} \mathrm{C}$, leg: $69.5{ }^{\circ} \mathrm{C}$, and the lipid content was: front: $1.8 \%$, back: $1.5 \%$, leg: $1.3 \%$.

All samples were subjected to accelerated degradation at $80{ }^{\circ} \mathrm{C}$ and $65 \% \mathrm{RH}$ for 18 days. Thus, we obtained a dataset of 78 samples based on Set I. Shrinkage temperature was determined for all these samples.

With the goatskin parchment from 2005 and another parchment sample from 1965, both relatively undegraded, we investigated the influence of initial lipid content (as determined using extraction with hexane), on accelerated degradation. As evident from Figure 1, there is a distinct influence of lipids on the changes of thermo-mechanical properties of collagen during degradation, as determined using shrinkage temperature measurements. This is the first piece of direct evidence showing the relationship between lipid content and degradation of parchment, although this has been indicated before [4] and the extent of autoxidation in parchment has been linked to lipid content [7]. The effect of lipids is considerable, taking into account that the removal of $3 \%$ lipids leads to a marked additional decrease of shrinkage temperature of $27 \%$, compared to samples with no extracted lipids.

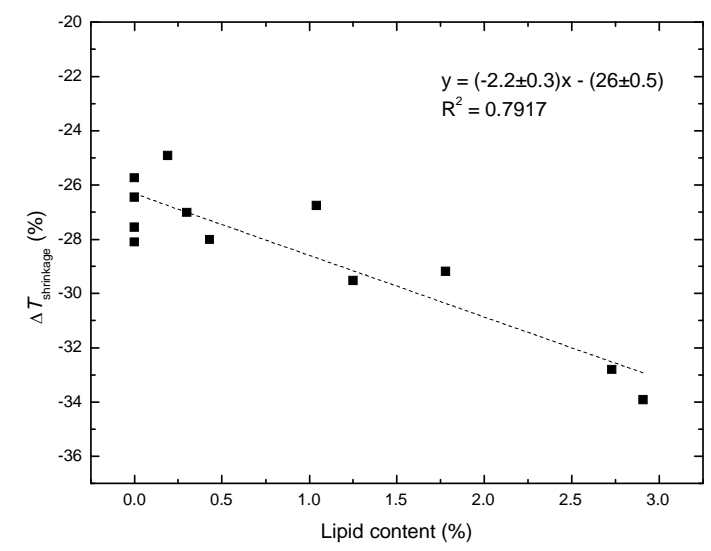

Figure 1. Decrease in shrinkage temperature of parchment samples from 1965 and 2005 during accelerated ageing, in dependence of their lipid contents.

However, lipid content could itself affect shrinkage temperature measurements. To examine the relationships between different factors affecting the shrinkage of collagen in parchment, i.e. percent of extracted lipids, accelerated degradation and age, we performed PCA on samples from Set I, taking into account the differently extracted and degraded samples, as well. The loading plot resulting from this analysis (Figure 2) is very interesting, as it reveals that shrinkage temperature is most affected by 
sample age and accelerated ageing, while the presence of lipids has no effect on shrinkage temperature measurements.

On the other hand there appears to be only a small effect of lipids on accelerated degradation. Lipids in parchment can namely originate from the original dermal layer of the animal skin, but they can also be introduced during production, conservation interventions, or handling [4, 7]. Thus, lipids of different origins may have stronger or weaker influence on collagen degradation.

The influence of the original lipid from animal skin, which survived the process of parchment production, may well be the most important, as it is contained in the original skin structure [4]. While in Figure 1 we show the pronounced effect of lipid content on degradation of two relatively new parchments, this effect is not apparent using a very diverse historic sample set because of the lack of information on past conservation treatments and production methods.

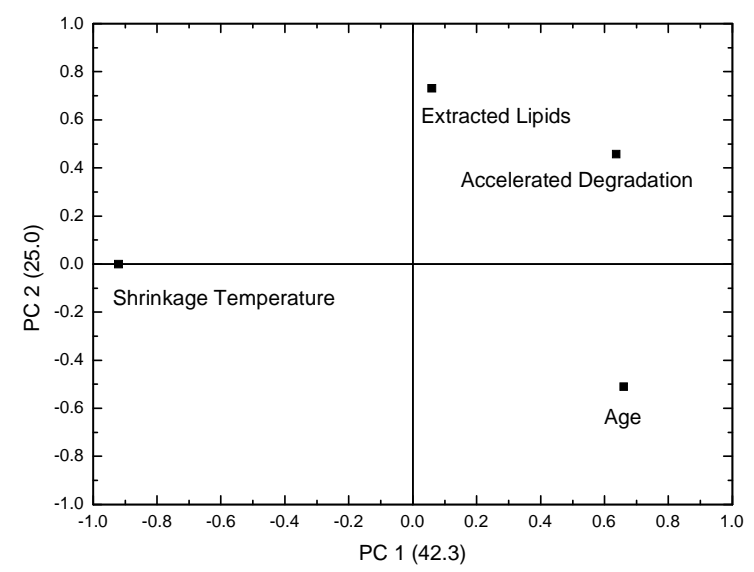

Figure 2. Principal component analysis loading plot for the principal component analysis of data for Set I: shrinkage temperature of all samples, age of samples, extracted lipids (\%), and accelerated degradation (whether carried out or not).

\section{Determination of shrinkage temperature based on NIR spectroscopy and chemometrics}

Since shrinkage temperature is such an important indicator of parchment condition [16], development of non-destructive methods of its determination is of high interest. For this purpose, we collected VIS/NIR spectra (450-2000 $\mathrm{nm}$ ) of all Set I samples, including all the extracted and degraded samples. Two different attachments were used: the ASD Chem Probe with a purpose-made accessory for reflectance measurements, and the ASD MuG-Light accessory with an external source. Using partial least square calibration, we then investigated whether NIR spectral information could be correlated with shrinkage temperature measurements.

We first studied whether the side on which a measurement is done is of importance due to the two different sides of a parchment skin having unique characteristics. The outer (skin) side, named recto, is more compact and may carry traces of hair follicles. The inner (flesh) or verso side is rougher and was usually preferred for writing. While surface characteristics of samples could affect the spectra, it was also of interest whether different spectral information is obtained on the verso and on the recto side. On the basis of previous work with paper [21], where it was shown that NIR radiation could collect 
information from up to 5 layers of paper, i.e. approximately $0.5 \mathrm{~mm}$ thick, it is reasonable to assume that for all but the thickest parchments, NIR spectra will contain information from the whole thickness of a sample. It is therefore not surprising that spectra taken on the recto and on the verso sides do not group into two distinct groups, using PCA (Figure 3).

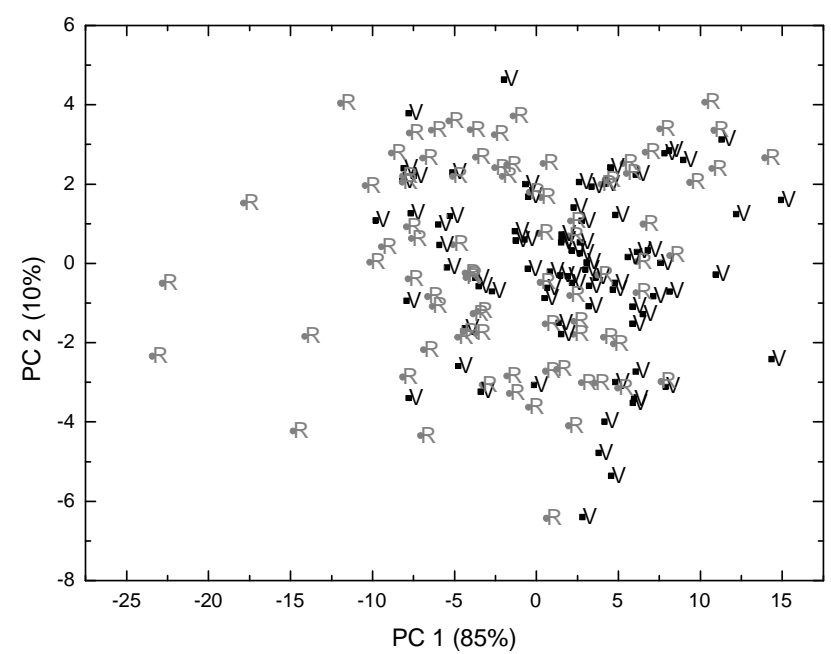

Figure 3: Principal component analysis of spectral data for all parchment samples from Set I, irrespective of pre-treatment $(\mathrm{N}=82)$. $\mathrm{V}$ marks verso side of parchment and $\mathrm{R}$ recto side of parchment.

PLS models were then built for determination of shrinkage temperature. In Table 1 and Figure 4, calibration and validation data are presented for three PLS calibrations $(\mathrm{N}=57)$ and validations using an independent set of samples $(\mathrm{N}=25)$. SNV, derivation and Martens' uncertainty test were used for spectral pre-treatment. Spectra were collected using the ASD Chem Probe with a purpose-made accessory on both sides of a parchment sample (recto and verso), and models were built for the two spectral sets separately, and combined.

Table 1. Partial least squares calibration and validation data for determination of shrinkage temperature of parchment.

\begin{tabular}{|l|l|l|l|l|l|l|l|l|}
\hline & \multicolumn{2}{l}{ Calibration } & \multicolumn{2}{l|}{ Validation } \\
\hline & Slope & Offset & RMSEC $\left[{ }^{\circ} \mathrm{C}\right]$ & $\mathrm{R}^{2}$ & Slope & Offset & RMSEV $\left[{ }^{\circ} \mathrm{C}\right]$ & $\mathrm{R}^{2}$ \\
\hline Verso & 0.80 & 9.2 & 4.6 & 0.80 & 0.86 & 4.5 & 6.7 & 0.69 \\
\hline Recto & 0.82 & 8.6 & 4.4 & 0.82 & 0.75 & 10.8 & 6.7 & 0.65 \\
\hline Combined & 0.82 & 8.4 & 4.3 & 0.82 & 0.71 & 12.3 & 7.1 & 0.60 \\
\hline
\end{tabular}



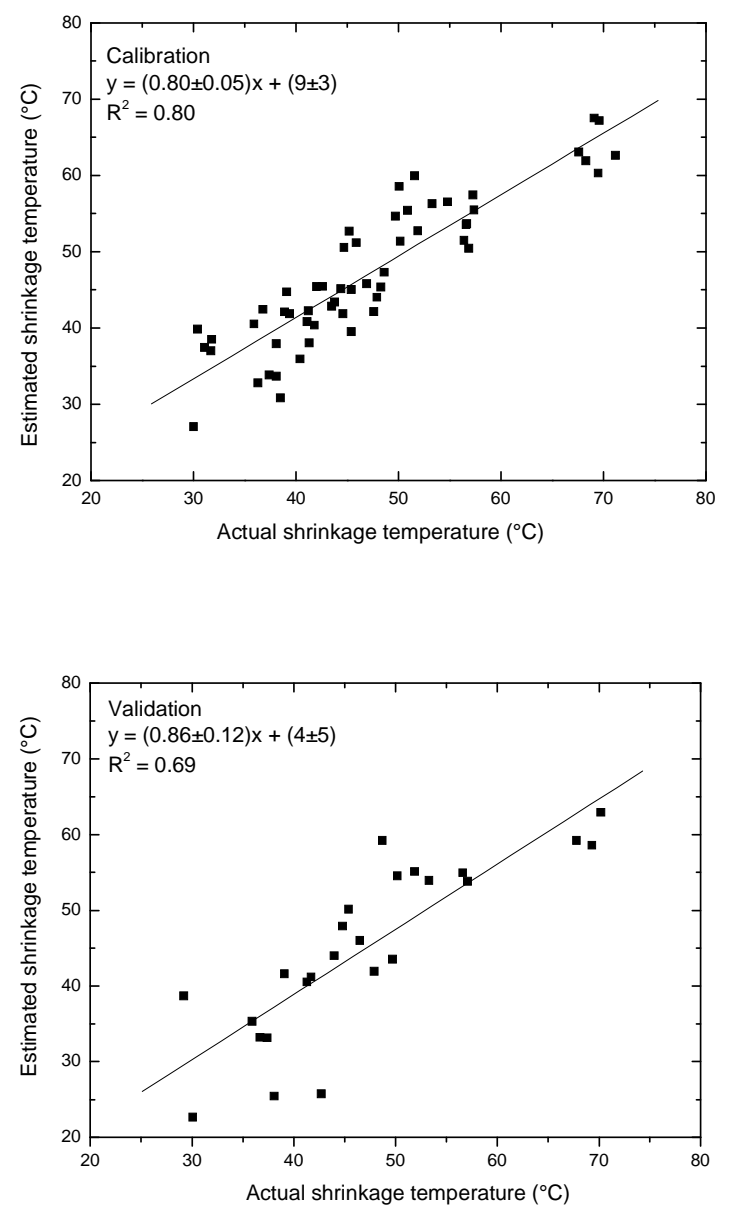

Figure 4. Partial least squares calibration (above) and validation (below) for determination of shrinkage temperature of parchment. All spectra were taken with the ASD Chem Probe with a purpose-made accessory on verso sides of parchment sample.

The obtained calibration thus enables us to determine the shrinkage temperature with the RMSEV of 7 ${ }^{\circ} \mathrm{C}$. The error does not allow us to determine very subtle differences; however, since the NIR technique is entirely non-destructive, it is attractive for evaluation of parchment condition and categorisation. Part of the error is undoubtedly due to the fact that shrinkage temperature is determined using a few fibres only, while the illuminated area is about 2-12 $\mathrm{mm}$ in diameter (depending on the accessory used) and thus the two samples are not identical.

On the other hand, the sample set was extremely heterogeneous and consisted of differently pre-treated parchments (extraction, degradation), which are not identical to historic samples. A method developed using a larger and representative sample set of historic parchments might lead to better results.

\section{Dating of historic parchment}

In this experiment, we investigated whether non-destructive dating of parchment could be performed based on NIR spectra. Since the spectra contain diverse chemical and structural information, it is 
feasible that subtle differences in the spectra occur as a result of parchment natural ageing and consequential changes in chemical composition. We used the historical parchments in Set II to build a PLS model for determination of the year of production (i.e. for dating). Interestingly, while all of the objects from the Nationaal Archief were dated between 1179 and 1793, one of them was dated with considerable uncertainty, i.e. it was unclear whether it was produced in 1314 or 1469 . The developed method, if of suitable accuracy, could therefore be used immediately to solve a particular curatorial question.

The parchment documents within Set II had very different surface properties, depending on the type of animal skin, procedure used in parchment production, storage history, and conservation interventions. Nevertheless, it was possible to build an acceptable model (Table 2, Figure 5), which enables us to date real historic parchments non-destructively. In Table 2, PLS calibration data for dating of historic parchment ( $\mathrm{N}=129$ using ASD Chem Probe or 123 using ASD MuG-Light) and validation data using an independent set of samples ( $\mathrm{N}=52$ using ASD Chem Probe or 51 using ASD MuG-Light). SNV, derivation and Martens' uncertainty test were used for spectral pre-treatment. Spectra were taken on recto and verso and models were built using the combined spectral set.

Table 2. Partial least squares calibration and validation data for dating of historic parchment documents $(\mathrm{N}=129)$ from the collection of Nationaal Archief, cf. Fig. 6.

\begin{tabular}{|l|l|l|l|l|l|l|l|l|}
\hline & \multicolumn{9}{|l|}{ Calibration } & \multicolumn{2}{l|}{ Validation } \\
\hline & Slope & Offset & RMSEC [years] & $\mathrm{R}^{2}$ & Slope & Offset & RMSEV [years] & $\mathrm{R}^{2}$ \\
\hline Chem Probe & 0.86 & 213 & 63 & 0.86 & 0.76 & 368 & 87 & 0.74 \\
\hline MuG-Light & 0.87 & 187 & 58 & 0.87 & 0.80 & 299 & 72 & 0.82 \\
\hline
\end{tabular}

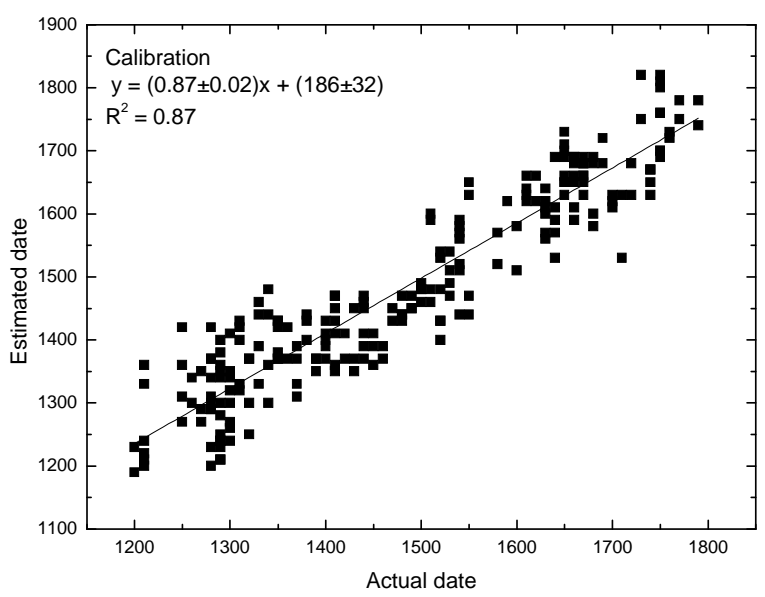




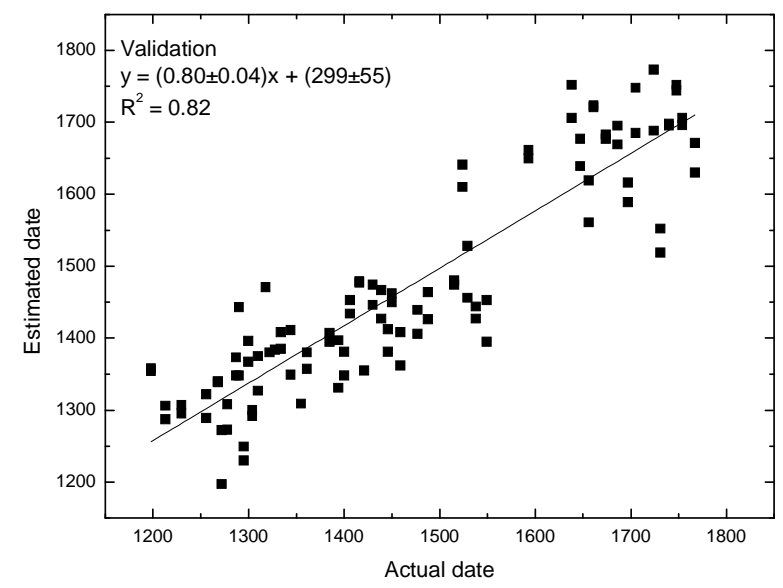

Figure 5. Partial least squares calibration (above) for dating of historic parchment, $N=123$, and validation (below, independent set of samples, $\mathrm{N}=51$ ). All spectra were taken with ASD MuG-Light.

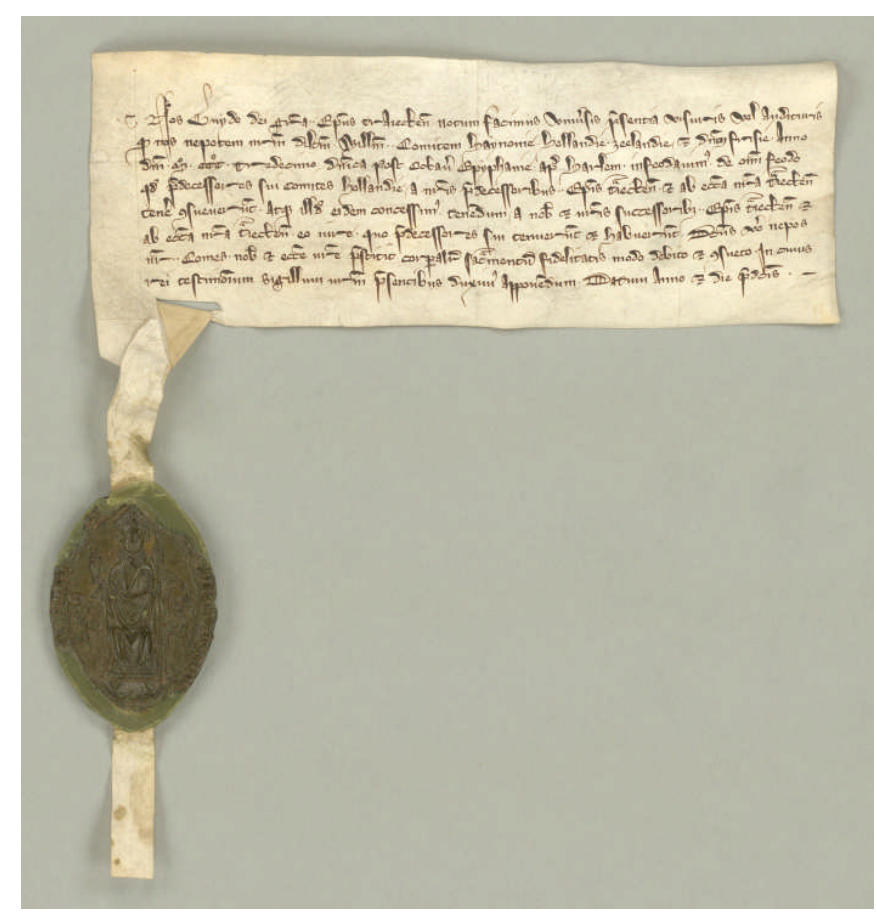

Figure 6. The parchment document from Nationaal Archief, The Netherlands, now reliably dated to be from 1314. The charter is from the archive of Graven van Holland, inv. No. 189.

With the developed method, it was now possible to date the archival document which was uncertainly dated (Figure 6). Spectra were taken on the recto and on the verso side using both accessories and the following determinations were obtained with ASD Chem Probe: verso - 1336, recto - 1313, and with ASD MuG-Light: verso - 1293, recto - 1316. The RMSEV values of 87 years for the ASD Chem Probe and 72 years for the ASD MuG-Light accessory thus enable us to confidently date the parchment document to be from year 1314 and not from 1469. Calligraphic analysis confirms the handwriting to be a typical early $14^{\text {th }}$ Century "clerk hand", which validates the results of material analysis using NIR. 
While the transfer of this method to other types of parchment and parchment collections would need to be investigated, the NIR and chemometrics based method is presently the only non-destructive dating method available for parchment.

\section{CONCLUSIONS}

We investigated the degradation and non-destructive characterisation of a large set of historic parchments. Using various sample preparation methods, including removal of lipids with extraction and thermo-oxidative degradation, we investigated the influence of various parameters on the determination of shrinkage temperature, which is indicative of the thermo-mechanical properties of historic parchment. We also investigated the possibilities of using near infrared spectroscopy for nondestructive characterisation and dating of highly valuable historic parchment objects. We have shown that:

- There is a significant effect of lipids present in new parchment on its degradation. The higher the lipid content, the faster is the degradation: a $3 \%$ lipid content led to $27 \%$ additional decrease of shrinkage temperature during accelerated ageing.

- While lipids contained in historic parchment do not affect the measurement of shrinkage temperature, they also do not significantly correlate with their degradation, which could be due to the various possible sources of lipids in historic parchment, including later conservation treatments.

- Based on NIR spectroscopy and partial least square calibration, we developed a nondestructive method for determination of parchment shrinkage temperature. The method could be used for rapid condition assessment of historic objects.

- Using a set of 185 historic objects from the collection of the National Archives in the Netherlands, we also developed a method for non-destructive dating of parchment and successfully determined the correct age of a historic charter.

The research demonstrates the use of portable spectroscopic instruments for historic parchment characterisation and dating in non-laboratory environments, based on NIR spectroscopy and chemometrics. It will also lead to better understanding of the key environmental parameters affecting parchment degradation and to better preservation of historic parchment collections.

\section{ACKNOWLEDGMENTS}

The work was financially supported by the Slovenian Research Agency (programme P1-0153, project L1-2401 and project BI-RO 016/2008-2009). The authors gratefully acknowledge the support of the Nationaal Archief (The Hague, The Netherlands). Further support for a short-term scientific mission was obtained from COST D42. We are grateful to Dr. Yvonne Bos-Rops for her expert calligraphic analysis.

\section{REFERENCES}


1 P. Budrugeac, L. Miu, V.Bocu, F.J. Wortman, C. Popescu: J. Therm. Anal. Cal. 72, 1057 (2003)

2 P. Budrugeac, L. Miu, C. Popescu, F.J. Wortman: J. Therm. Anal. Cal. 77, 975 (2004)

3 C. Popescu, P. Budrugeac, F.J. Wortmann, L. Miu, D.E. Demco, M. Baias: Polym. Degrad. Stab. 93, $976(2008)$

4 C. Ghioni, J.C. Hiller, C.J. Kennedy, A.E. Aliev, M. Odlyha, M. Boulton, T.J. Wess: J. Lip Res. 46, $2726(2005)$

5 A.J. Bailey, R.G. Paul: J. Soc. Leath. Technol. Chem. 82, 104 (1998)

6 C. Chahine: Thermochim. Acta 365, 101 (2000)

7 M. Strlič, I. Kralj Cigić, I. Rabin, J. Kolar, B. Pihlar, M. Cassar: Polym. Degrad. Stab 94, 6886 (2009)

8 M. Odlyha, C. Theodorakopoulos, J. de Groot, L. Bozec, M. Horton: Thermoanalytical (macro to nanoscale) techniques and non-invasive spectroscopic analysis for damage assessment of parchment, in: Improved Damage Assessment of Parchment, IDAP EC Research report No. 18, (ISBN 978-92-70-05378-8)

9 S.N. Cohen, M. Odlyha, G.M. Foster: Thermochim. Acta 365, 111 (2000)

10 R. Larsen, M. Vest, K.J. Nielsen: J. Soc. Leath. Technol. Chem. 77, 151 (1993)

11 L. Puchinger, S. Pentzien, R. Koter, W. Kautek: Spinger Proceedings, Physics 100, 51 (2004)

12 R. Larsen: Summery, Discussion and Conclusion. STEP Leather project. Protection and Conservation of European Cultural Heritage. Report No. 1. (1994), p. 151.

13 R. Larsen: Summery, Discussion and Conclusion. STEP Leather project. Protection and Conservation of European Cultural Heritage. Report No. 4. (1994), p. 145.

14 M. Odlyha, C. Theodorakopoulos, J. de Groot, L. Bozec, M. Horton: e-Preserv. Sci. 6, 138 (2009)

15 P. Budrugeac, E.Badea, G. Della Gatta, L. Miu, A. Comănescu: Thermochim. Acta 500, 51 (2010)

16 R. Larsen: Microanalysis of Parchment (Archetype Publications London UK 2002)

17 R. Inagi, T. Miyata: Blood Purif. 17, 95 (1999)

18 T. Miyata, R. Inagi, K. Asahi, Y. Yamada, K. Horie, H. Sakai, K. Uchida, K. Kurokawa: FEBS Lett. 437, 24 (1998)

19 B. Dolgin, V. Bulatov, I. Schechter: Rev. Anal. Chem. 151, 28 (2009)

20 G. W. Small: Tr. Anal. Chem. 25, 11 (2006)

21 T. Trafela, M. Strlič, J. Kolar, D.A. Lichtblau, M. Anders, D. Pucko Mencigar, B. Pihlar: Anal. Chem. 79, 6319 (2007)

22 H.W. Siesler, Y. Ozaki, S. Kawata, H.M. Heise: Near-Infrared Spectroscopy. Principles, Instruments, Applications (Wiley-VCH Weinheim Germany 2002)

23 S.C.C. Wiedemann, W.G. Hansen, M. Snieder, V.A.L. Wortel: Analusis Mag. 26, 4 (1998) 
24 P. Chaminade, A. Baillet, D. Ferrier: Analusis Mag. 26, 4 (1998)

25 R. Karmer: Chemometric Techniques for Quantitative Analysis (Dekker New York NY 1998) 